\title{
PUMA regulates germ cell loss and primordial follicle endowment in mice
}

\author{
Michelle Myers ${ }^{1,2}$, F Hamish Morgan ${ }^{1,2}$, Seng H Liew ${ }^{1}$, Nadeen Zerafa ${ }^{1}$, \\ Thilini Upeksha Gamage ${ }^{1}$, Mai Sarraj ${ }^{1}$, Michele Cook $^{3}$, Ileana Kapic ${ }^{1}$, Antony Sutherland ${ }^{1,2}$, \\ Clare L Scott ${ }^{3,4}$, Andreas Strasser ${ }^{3,4}$, Jock K Findlay ${ }^{1}$, Jeffrey B Kerr ${ }^{2}$ and Karla J Hutt ${ }^{1,2}$ \\ ${ }^{1}$ MIMR-PHI Institute of Medical Research, 27-31 Wright Street, Clayton, Victoria 3168, Australia, ${ }^{2}$ Department of \\ Anatomy and Developmental Biology, Monash University, Clayton, Victoria, Australia, ${ }^{3}$ The Walter and Eliza Hall \\ Institute of Medical Research, Melbourne, Victoria, Australia and ${ }^{4}$ Department of Medical Biology, The University \\ of Melbourne, Melbourne, Victoria, Australia
}

Correspondence should be addressed to KJ Hutt; Email: Karla.Hutt@princehenrys.org

\begin{abstract}
The number of primordial follicles initially established within the ovary is influenced by the extent of germ cell death during foetal ovarian development, but the mechanisms that mediate this death have not been fully uncovered. In this study, we identified BBC3 (PUMA) (p53 upregulated modulator of apoptosis, also known as BCL2-binding component 3), a pro-apoptotic BH3-only protein belonging to the BCL2 family, as a critical determinant of the number of germ cells during ovarian development. Targeted disruption of the $B b c 3$ gene revealed a significant increase in the number of germ cells as early as embryonic day 13.5. The number of germ cells remained elevated in $B b c 3^{-1-}$ female mice compared with WT female mice throughout the remainder of embryonic and early postnatal life, resulting in a 1.9-fold increase in the number of primordial follicles in the ovary on postnatal day 10 . The increase in the number of germ cells observed in the ovaries of $B b c 3^{-/-}$mice could not be attributed to the altered proliferative activity of germ cells within the ovaries. Furthermore, BBC3 was found to be not required for the massive germ cell loss that occurs during germ cell nest breakdown. Our data indicate that BBC3 is a critical regulator of germ cell death that acts during the migratory phase of oogenesis or very soon after the arrival of germ cells in the gonad and that BBC3-mediated cell death limits the number of primordial follicles established in the initial ovarian reserve.
\end{abstract}

Reproduction (2014) $\mathbf{1 4 8} 211-219$

\section{Introduction}

Primordial follicles, comprising an immature oocyte surrounded by a single layer of squamous granulosa cells, are the storage unit for the female germ line (Hutt et al. 2006). Despite recent controversy (Byskov et al. 2005, Telfer et al. 2005, Skaznik-Wikiel et al. 2007, Kerr et al. 2012a), it is widely believed that the pool of primordial follicles present in the ovary at birth represents the entire complement of oocytes available to females throughout their reproductive life, with all oocytes for subsequent ovulation being derived from this initial stockpile. From birth onwards, the number of primordial follicles steadily declines until the pool becomes exhausted, leading to the end of fertility, followed by the beginning of menopause in women (Faddy \& Gosden 1995). The mechanisms that control the size of the primordial follicle pool at birth are poorly understood. However, it is essential to understand this process because the duration of a woman's reproductive life is influenced by the number of primordial follicles with which she is endowed (de Bruin \& te Velde 2004).

The primordial follicle population is established by a series of events that occur during embryonic and neonatal development (Pepling 2006). In mice, the process of oogenesis begins at embryonic (E) day 7.5 with the allocation of the embryonic precursors of adult gametes, known as primordial germ cells (Tam \& Snow 1981, Lawson \& Hage 1994). The germ cells migrate from the base of the allantois through the hindgut and begin to colonise the genital ridge at E11.5 (McLaren 1988, 2000, Molyneaux \& Wylie 2004). Following their arrival in the developing gonad, the germ cells lose their motility and become oogonia. Primordial germ cells proliferate during their migration and continue to do so as oogonia after colonisation of the gonads, leading to a dramatic increase in the number of germ cells (Tam \& Snow 1981, Molyneaux \& Wylie 2004). The dividing oogonia are found clustered in germ cell nests, arising 
from incomplete cytokinesis and cell aggregation (Pepling \& Spradling 1998, Lei \& Spradling 2013). At E13.5, the first oogonia cease to proliferate, begin to enter the early stages of meiosis and differentiate into primary oocytes (Borum 1961). The transition from mitosis to meiosis, occurring between E13.5 and E15.5 in mice, corresponds to the peak in germ cell number. Around the time of birth, and coincident with a massive wave of germ cell loss, the nests break down. The individual oocytes then arrest in meiosis I at diplotene and are enclosed in a layer of granulosa cells, becoming primordial follicles. In mice, the entire process of follicle formation is complete around postnatal (PN) day 5 (Pepling 2006). In humans, the process of primordial follicle endowment is analogous, with the peak in germ cell number occurring at mid-gestation and the completion of primordial follicle assembly occurring before birth (Motta et al. 1997).

Apoptosis probably occurs at all stages of oogenesis, but is currently best characterised during the mitoticmeiotic transition (mouse, E13.5-E15.5) and nest breakdown (mouse, E17.5-PN3) (Coucouvanis et al. 1993, Pepling \& Spradling 2001, McClellan et al. 2003), when the number of germ cells declines dramatically. The reason behind the massive depletion is not known, though it has been suggested that apoptosis may be required for nest breakdown to enable individual primordial follicles to assemble (Pepling \& Spradling 2001) and/or to ensure that defective or low-quality oocytes (e.g. those with DNA damage) are eliminated (Pepling \& Spradling 2001, Tilly 2001). It is likely that germ cells express a number of apoptotic regulators, providing them with flexibility to respond to a wide variety of death signals, ensuring that only the 'best' oocytes survive. However, the physiological triggers of germ cell death and the pathways mediating their demise have not been fully characterised.

BBC3 (PUMA) (p53 upregulated modulator of apoptosis, also known as BCL2-binding component 3) is a pro-apoptotic protein that belongs to the $\mathrm{BH} 3$-only subgroup of the $\mathrm{BCL} 2$ protein family. Interactions between the BH3-only proteins (BBC3, BCL2L11 (BIM), BID, BMF, PMAIP1 (NOXA), BAD, BIK and $\mathrm{HRK}$ ), the BAX/BAK pro-apoptotic subgroup and the pro-survival $\mathrm{BCL} 2$ family members (BCL2, BCL2L1 (BCL-XL), BCL2L2 (BCL-W), MCL1 and A1) control the intrinsic (also called 'mitochondrial', 'BCL2-regulated' or 'stress') apoptosis pathway (Happo et al. 2012). BBC3 contains a small $\mathrm{BH} 3$ domain, which is essential for its apoptosis-initiating function. $\mathrm{BH} 3$-only proteins are activated transcriptionally and post-transcriptionally by developmental cues and a broad range of cytotoxic insults (Strasser et al. 2000). The BH3-only proteins initiate apoptosis by binding to the pro-survival BCL2 family members (Happo et al. 2012). This interaction relieves the inhibition of 'primed' pro-apoptotic BAX/ BAK at the mitochondrial membrane, which results in cytochrome $c$ release, apoptosome formation, caspase activation and consequent cellular demolition. BBC3 and certain other $\mathrm{BH} 3$-only proteins (BCL2L11 and $\mathrm{BBID}$ ) may also initiate apoptosis through direct binding of BAX/BAK (Merino et al. 2009, Happo et al. 2012). BBC3 (alongside BCL2L11 and tBID) is a particularly potent inducer of apoptosis because it can bind with high affinity to all pro-survival BCL2 family members, whereas other $\mathrm{BH} 3$-only proteins (e.g. BAD and PMAIP1) have a restricted binding profile (Willis et al. 2007).

We have previously shown that the DNA damageinduced apoptosis of primordial follicle oocytes is mediated by the transcriptional activation of BBC3 by TAp63 (Kerr et al. 2012b), highlighting an essential role for BBC3 in the elimination of oocytes following genotoxic stress during meiotic arrest. We also found that the initial pool of primordial follicles established within the ovary of PN10 $B b c 3^{-/-}$mice was significantly larger than that of WT controls (Kerr et al. $2012 b$ ), indicating that BBC3 is required for developmentally regulated apoptosis within the female germ line. In the present study, we determined the role of BBC3-mediated cell death during the migratory and/or mitotic germ cell stage. The results indicate that a significant number of germ cells are lost early in development and these early germ cell losses significantly affect the number of primordial follicles established in the initial ovarian reserve.

\section{Materials and methods}

\section{Mice}

$B b c 3^{-1-}$ mice on a C57BL/6 background were generated and genotyped as described previously (Villunger et al. 2003). Mice were maintained under a $12 \mathrm{~h}$ light: $12 \mathrm{~h}$ darkness cycle in a temperature-controlled pathogen-free facility with free access to mouse chow and water. Timed matings were set up to allow the collection of embryos, and the morning a vaginal plug was detected was designated as E0.5. Animal procedures were approved by the Animal Ethics Committee of Monash University and the Walter and Eliza Hall Institute and were carried out in accordance with the Australian Code of Practice for the Care and Use of Animals for Scientific Purposes.

\section{Germ cell stereology}

Ovaries from E13.5, E15.5, E17.5, PN3, PN5 and PN10 WT and $B b c 3^{-1-}$ embryos ( $n=3-7 /$ genotype) to be used for stereology were fixed in Bouin's solution and processed into hydroxyethyl methacrylate resin (Technovit 7100; Kulzer \& Co., Friedrichsdorf, Germany). Ovaries were serially sectioned $(20 \mu \mathrm{m})$ with a Leica RM2165 microtome (Leica Microsystems Nussloch $\mathrm{GmbH}$, Nussloch, Germany) and stained with periodic acidSchiff and counterstained with haematoxylin. Stereological data were obtained using the optical dissector/fractionator technique as described previously (Myers et al. 2004, Kerr et al. 2006) using a $\times 100$ oil-immersion objective on an Olympus 
BX50 microscope equipped with an Autoscan stage (Autoscan Systems Pty Ltd, Melbourne, VIC, Australia) in conjunction with the CASTGRID stereological system (CAST 2002; Olympus). CAST is a Computer Assisted Stereological Toolbox that enables the automatic sampling of ovarian tissue sections for unbiased and efficient stereological estimation of germ cell number. Every third section, beginning from a random start, was evaluated and the number of follicles in the ovary was determined by multiplying the raw count of oocytes sampled $\left(Q^{-}\right)$with all the three sampling fractions $\left(1 / f_{1}, 1 / f_{2}\right.$ and $\left.1 / f_{3}\right)$ as described previously (Myers et al. 2004). This is achieved through sampling of three parameters: sections, depth and field.

\section{TUNEL assay}

Ovaries were fixed in $4 \%$ paraformaldehyde or formalin, dehydrated, embedded in paraffin, serially sectioned $(5 \mu \mathrm{m})$ and mounted on glass slides. The Apop Tag Peroxidase In Situ Apoptosis Detection Kit (Millipore, Temecula, CA, USA) was used to detect apoptosis according to the manufacturer's instructions. The sections were counterstained with haematoxylin. To compare the numbers of apoptotic cells between WT and $B b c 3^{-1-}$ ovaries, three to five sections per ovary per animal ( $n=3-5$ animals/age per genotype) were analysed using the TUNEL assay. The number of TUNEL-positive cells (mean \pm S.E.M.) is expressed per $10^{4} \mu \mathrm{m}^{2}$ ovarian tissue area using a methodology described previously (Kerr et al. 2012b).

\section{Immunofluorescence and immunohistochemistry}

As has been described above, $5 \mu \mathrm{m}$ sections were cut for immunohistochemistry ( $n=3-5$ animals/age per genotype). Antigen retrieval was performed by microwaving the sections for $10 \mathrm{~min}$ in $0.01 \mathrm{M}$ citrate buffer $(\mathrm{pH} \mathrm{6)}$. Endogenous peroxidases were quenched for $30 \mathrm{~min}$ in $0.3 \% \mathrm{H}_{2} \mathrm{O}_{2}$, and non-specific binding of antibodies was blocked by incubating the sections for $1 \mathrm{~h}$ with $10 \%$ normal goat serum. The sections were then incubated with primary antibody against BBC3 (1:200; Abcam) (previously validated by us in mouse ovaries and shown to specifically recognise BBC3 (Kerr et al. 2012b) for $1 \mathrm{~h}$ at $37^{\circ} \mathrm{C}$ or overnight at $4{ }^{\circ} \mathrm{C}$ and later with biotinylated goat antibody against rabbit IgG (1:400; Zymed (San Francisco, CA, USA); secondary antibody) for $1 \mathrm{~h}$ at room temperature. The sections were incubated for a further $30 \mathrm{~min}$ with the avidin-biotin peroxidase complex (Vector Laboratories, Burlingame, CA, USA), and peroxidase activity was visualised using 3,3'-diaminobenzidine as the substrate. The sections were counterstained with haematoxylin. Cells stained with Ig isotype-matched control antibodies or with the primary antibody omitted were used as negative controls. Additionally, the specificity of the antibody against BBC3 was confirmed using $B b c 3^{-/-}$ovarian tissue sections as negative controls; no staining was observed.

The primary antibodies used for immunofluorescent staining were specific to DDX4 (MVH) (1:800; Abcam), H2AFX ( $\gamma \mathrm{H} 2 \mathrm{AX})$ (1:500; Abcam), phosphohistone-3 (PH3; Ser28) (1:200; Upstate, Lake Placid, NY, USA) and TRP63 (TAP63) (gift from Dr F McKeon (Suh et al. 2006)). Antigen retrieval and blocking were performed as described above. After incubation with primary antibodies overnight at $4{ }^{\circ} \mathrm{C}$, the sections were incubated at room temperature for $1 \mathrm{~h}$ with Alexa568-conjugated goat antibodies against mouse IgG (1:1000; Jackson ImmunoResearch Laboratories, West Grove, PA, USA) or Alexa488-conjugated goat antibodies against rabbit IgG (1:1000; Molecular Probes, Mulgrave, VIC, Australia). The sections were counterstained with TOPR03 (Molecular Probes). Slides were mounted with Fluorsave (Millipore, Temecula, CA, USA) and analysed by fluorescent confocal microscopy using an Olympus IX81 microscope.

The proportions of mitotic germ cells were estimated by dividing the number of germ cells positive for both $\mathrm{PH} 3$ and DDX4 by the total number of DDX4-positive germ cells in three to five sections per ovary per animal ( $n=3-5$ animals/age per genotype). Care was taken that a middle cross-section and at least one section on either side were analysed. Similar sampling was performed to determine the timing of meiotic progress (i.e. $\gamma \mathrm{H} 2 \mathrm{AX}$ staining) and meiotic arrest (i.e. TAp63 staining).

\section{Statistical analysis}

Data are presented as means \pm s.E.M., and statistical analysis was carried out using GraphPad Prism Software (GraphPad Software, Inc., La Jolla, CA, USA). Two-tailed unpaired $t$-tests were used for single comparisons of WT and $B b c 3^{-1-}$ ovaries for each age. For each age, three to seven ovaries were assessed, and $P<0.05$ was considered statistically significant.

\section{Results}

\section{BBC3 expression during ovarian development}

The expression of BBC3 protein was assessed by immunohistochemistry in the ovaries of WT mice (Fig. 1). BBC3 was weakly detected, represented by diffuse staining, throughout the ovaries at E13.5 and E15.5. At E17.5, BBC3 was undetectable in germ cells, though some weak somatic cell staining was observed. BBC3 was undetectable in somatic cells, naked oocytes and primordial follicles at PN1, PN3 and PN5. However, the oocytes of some growing follicles, present in the ovary as early as PN3, expressed BBC3.

\section{Germ cell and follicle numbers are elevated in embryonic and early postnatal Bbc3 $3^{-1-}$ ovaries}

Germ cells and follicles were enumerated in the ovaries of WT and $B b c 3^{-/-}$mice during embryonic and early postnatal development. The number of germ cells per ovary was elevated in $B b c 3^{-1-}$ embryos compared with their WT counterparts as early as E13.5 (2850 \pm 354 WT vs $6408 \pm 738 \mathrm{Bbc}^{-/-}, P<0.05$; Fig. 2), which corresponds to the period when germ cells undergo proliferation to form germ cell nests. The number of germ cells was still elevated in the ovaries of $B b c 3^{-/-}$mice at E15.5, though the difference when compared with WT controls was not significant $(14587 \pm 1280$ WT vs $\left.21059 \pm 3440 \mathrm{Bbc}^{-/-}, P=0.45\right)$. At E17.5, the ovaries of WT mice contained $13981 \pm 4052$ germ cells, 

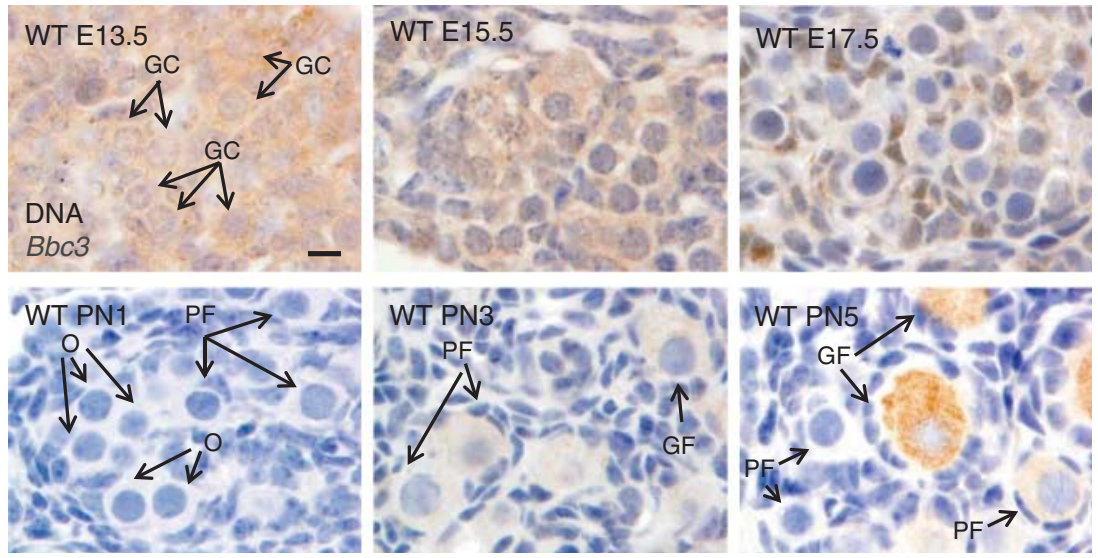

Figure 1 BBC3 expression during ovarian development. $\mathrm{BBC} 3$ expression was examined in the ovaries of E13.5-PN5 WT mice by immunohistochemistry (brown). Data are representative of $n=3-5$ animals/age. GC, germ cell; $\mathrm{O}$, oocyte; $\mathrm{PF}$, primordial follicle; GF, growing follicle. Scale bar: $10 \mu \mathrm{m}$. whereas those of $\mathrm{Bbc}^{-1-}$ mice contained $24984 \pm$ 4052 germ cells $(P<0.05)$. Between E17.5 and PN10, the period when germ cell nests break down and primordial follicles assemble, there was a reduction in the number of germ cells in the ovaries of both WT and $\mathrm{BbC}^{-1-}$ mice. However, the number of germ cells remained significantly higher in the ovaries of $\mathrm{Bbc}^{-1-}$ mice than in those of WT mice at PN3 $(7111 \pm 978$ WT vs $\left.10923 \pm 966 \mathrm{Bbc}^{-/-}, P<0.05\right)$ and PN10 (4534 \pm 396 WT vs $\left.8488 \pm 1233 \mathrm{Bbc}^{-/-}, P<0.05\right)$ (Fig. 2). Thus, the 2.2-fold increase in the number of germ cells in $\mathrm{BbC3}^{-/-}$mice at E13.5 was maintained throughout ovarian development and resulted in a 1.9-fold increase in the number of primordial follicles initially established in the ovary.

\section{Apoptosis in the developing ovary}

The TUNEL assay was used to assess apoptosis in the ovaries of WT and $B b c 3^{-/-}$mice throughout ovarian development (Fig. 3). Apoptotic cells were detected at all embryonic stages analysed (E13.5-E17.5), but there was no significant difference in the numbers of TUNELpositive cells detected in the ovaries of WT and $B b c 3^{-/-}$ mice. Apoptotic cells were also observed in similar numbers in the ovaries of both WT and $B b c 3^{-/-}$mice at PN1, the period when nest breakdown and follicle formation occur. Very low-to-negligible numbers of apoptotic cells were detected between PN3 and PN10.

\section{Proliferation is normal in $\mathrm{Bbc}^{-/-}$ovaries}

As increased numbers of cells can result from increased proliferation, mitosis was investigated by immunofluorescent staining for PH3 (a marker of mitotic cells) and DDX4 (a marker of germ cells) (Fig. 4A). The ovaries of E13.5 mice were selected for this analysis because germ cell proliferation occurs at E13.5. No significant difference was observed in the percentages of germ cells labelled with $\mathrm{PH} 3$ in the ovaries of $\mathrm{Bbc}^{-/-}$and
WT mice (Fig. 4B; WT $=7.2 \pm 1.0 \% ; B b c 3^{-/-}=7.9 \pm$ $0.6 \%)$.

\section{Timing of the mitotic-meiotic transition is normal in Bbc $^{-\prime-}$ ovaries}

Increased numbers of germ cells may also result if the proliferative period is prolonged. Therefore, the timing of meiotic progression was determined by immunostaining for the meiotic prophase marker H2AFX, which is expressed from leptotene to pachytene. The first H2AFX-positive oocytes were detected at E13.5 in the ovaries of both WT and $B b c 3^{-1-}$ mice, but these meiotic cells were rare (Fig. 5A and B). In contrast, by E15.5, the majority of oocytes were labelled with $\mathrm{H} 2 \mathrm{AFX}$, but again no differences were observed between the ovaries of WT embryos and those of $B b c 3^{-1-}$ embryos (Fig. 5B; E15.5: $\left.\mathrm{WT}=93 \pm 2 \% ; \mathrm{Bbc}^{-/-}=96 \pm 2 \%\right) . \gamma \mathrm{H} 2 \mathrm{AX}$ staining was no longer detected at PN3 in the oocytes of WT mice, although a very small number of oocytes in the ovaries of $\mathrm{BbC}^{-1-}$ mice exhibited persistent $\mathrm{H} 2 \mathrm{AFX}$ expression (Fig. 5A, white arrowhead). However, the

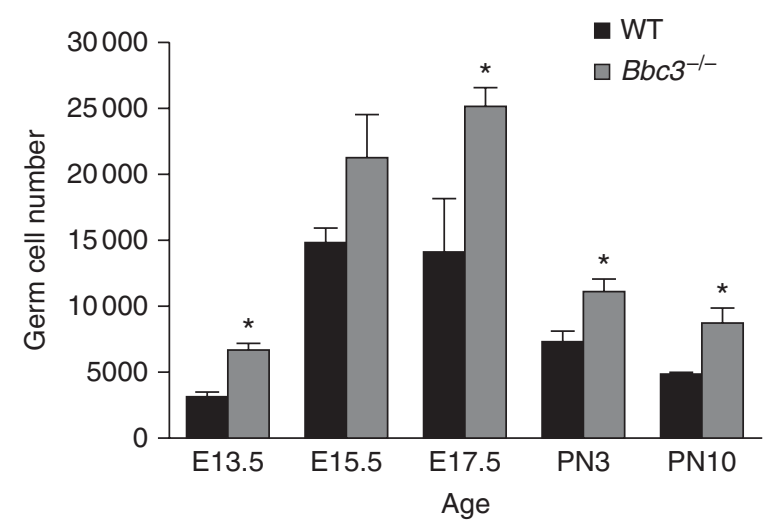

Figure 2 Germ cell numbers are abnormally elevated in $B b c 3^{-/-}$ ovaries compared with WT ovaries. Germ cells were counted in ovaries from E13.5 to PN10 ( $n=3-7$ animals/age per genotype). Data are expressed as means \pm s.E.M. ${ }^{*} P<0.05$ for comparison of $B b c 3^{-/-}$vs WT mice at each age. 


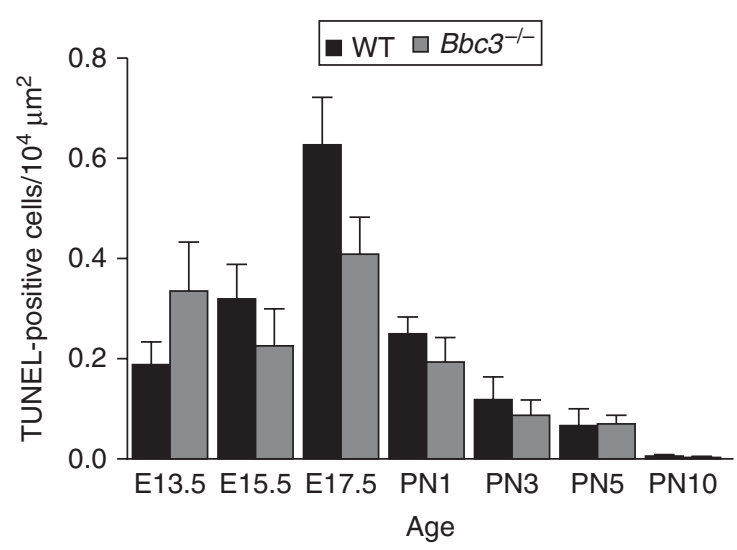

Figure 3 Germ cell apoptosis in $B b c 3^{-/-}$and WT ovaries during ovarian development. The number of apoptotic cells was determined by TUNEL staining in the ovaries of E13.5-PN10 WT and $B b c 3^{-/-}$ mice. Data are expressed as means \pm s.E.M.

expression of $\mathrm{H} 2 \mathrm{AFX}$ was no longer detected in the ovaries of either WT or $\mathrm{Bbc3}^{-1-}$ mice at PN5 (Fig. 5A and $\mathrm{B})$, the period when oocytes progress into diplotene arrest and follicle formation is complete.

\section{Entry into meiotic arrest is delayed in $\mathrm{Bbc} 3^{-1-}$ ovaries}

Entry into meiotic arrest was monitored by staining for TRP63 (Fig. 6A and B), which has previously been shown to be expressed by oocytes as they enter diplotene (Suh et al. 2006). At E17.5, oocytes from the ovaries of both WT and $B b c 3^{-1-}$ mice did not express TRP63 (Fig. 6A and B). At PN1, 33\% of the WT oocytes expressed TRP63, whereas TRP63 expression was not detected in any of the $B b c 3^{-/}$oocytes, indicating a slight delay in meiotic arrest in the ovaries of $B b c 3^{-1-}$ mice (Fig. 6A and $\mathrm{B})$. No differences were detected between the ovaries of WT mice and those of $\mathrm{Bbc}^{-1-}$ mice at PN3 and PN5, with the expression of TRP63 being detected in nearly all WT and $B b c 3^{-1-}$ oocytes (Fig. $6 \mathrm{~A}$ and B).

\section{$B B C 3$ is not required for nest breakdown}

It has previously been hypothesised that apoptosis is required for germ cell nest breakdown (Pepling \& Spradling 2001). Therefore, we investigated the role of BBC3-mediated apoptosis in germ cell nest breakdown by staining the ovaries of E13.5, E15.5, E17.5, PN1, PN3 and PN5 WT and $\mathrm{Bbc3}^{-1-}$ mice for the cytoplasmic germ cell marker DDX4 to clearly visualise nest morphology (Fig. 7). Between E13.5 and E17.5, the formation of germ cell nests was evident by the appearance of germ cell clusters. No morphological differences were observed in the progression of nest development between the ovaries of WT mice and those of $\mathrm{Bbc}^{-1-}$ mice during this period (Fig. 7). Furthermore, nest breakdown progressed normally in the ovaries of $\mathrm{Bbc3}^{-1-}$ mice between E17.5 and PN3 and was complete by PN5 in the ovaries of both WT and $B b c 3^{-1-}$ mice, as indicated by the formation of individual follicle-enclosed oocytes (Fig. 7).

\section{Discussion}

The number of oocytes stored in the ovary as primordial follicles influences female fertility and reproductive life duration. The size of the initial primordial follicle reserve at birth is limited by germ cell apoptosis during embryonic ovarian development, with more than twothirds of the germ cells being lost prior to and around the time of primordial follicle formation. Despite playing an essential role in ovarian development and female fertility, only a limited number of apoptotic regulators have been functionally characterised. We identified $\mathrm{BBC} 3$, a potent cell killer belonging to the $\mathrm{BH} 3$-only subgroup of the BCL2 family, as a key regulator of the germ cell number and primordial follicle endowment in mice. This finding, coupled with our recent investigations identifying $\mathrm{BBC} 3$ as a key initiator of DNA damage (elicited by $\gamma$-irradiation)-induced killing of primordial follicles during early postnatal development (PN5) (Kerr et al. 2012b), places BBC3 amongst the most important cell death regulators thus far identified in the female germ line.

Our data indicate that BBC3-mediated death has a marked effect on the number of germ cells retained at the
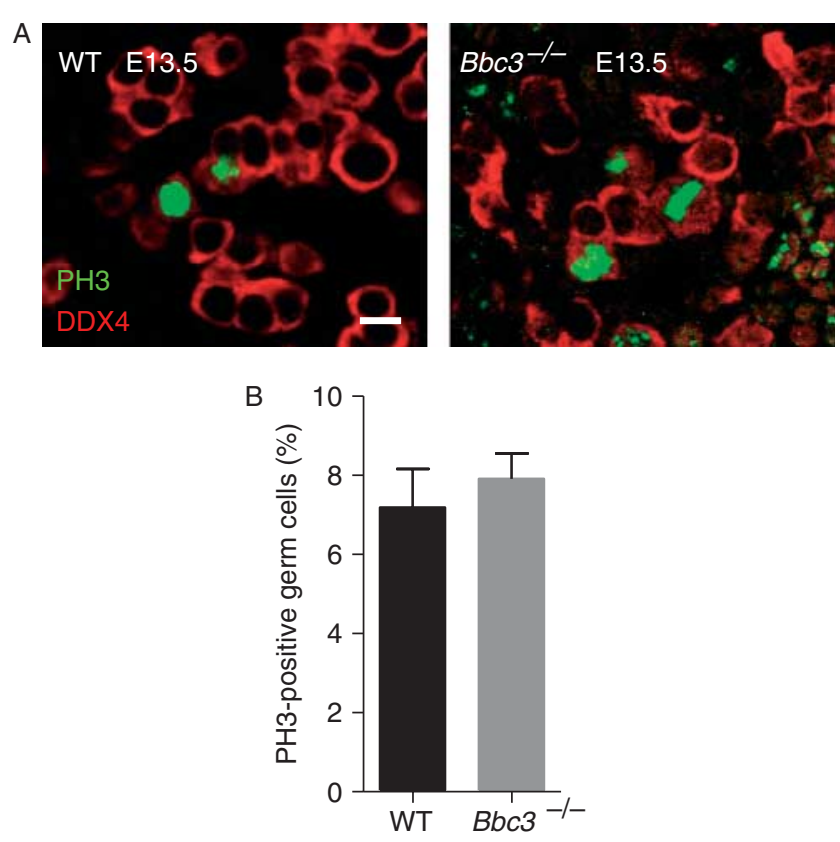

Figure 4 Proliferation is normal in $B b c 3^{-/-}$ovaries. (A) Proliferation was assessed in the ovaries of WT and $B b c 3^{-1-}$ mice at E13.5 using immunostaining for the mitotic marker phosphohistone-3 (PH3) (red) and the germ cell marker DDX4 (green). Scale bar: $10 \mu \mathrm{m}$. (B) The proportions of germ cells (DDX4 positive) that were also positive for $\mathrm{PH} 3$ were determined in the ovaries of WT and $\mathrm{Bbc}^{-1-}$ mice at E13.5. Data are expressed as means \pm S.E.M. 

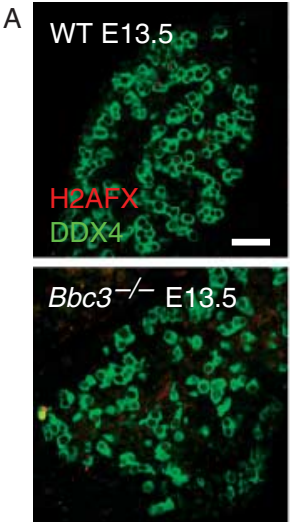
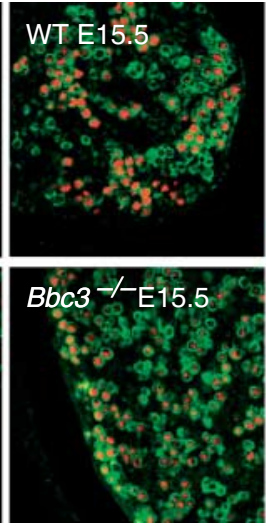
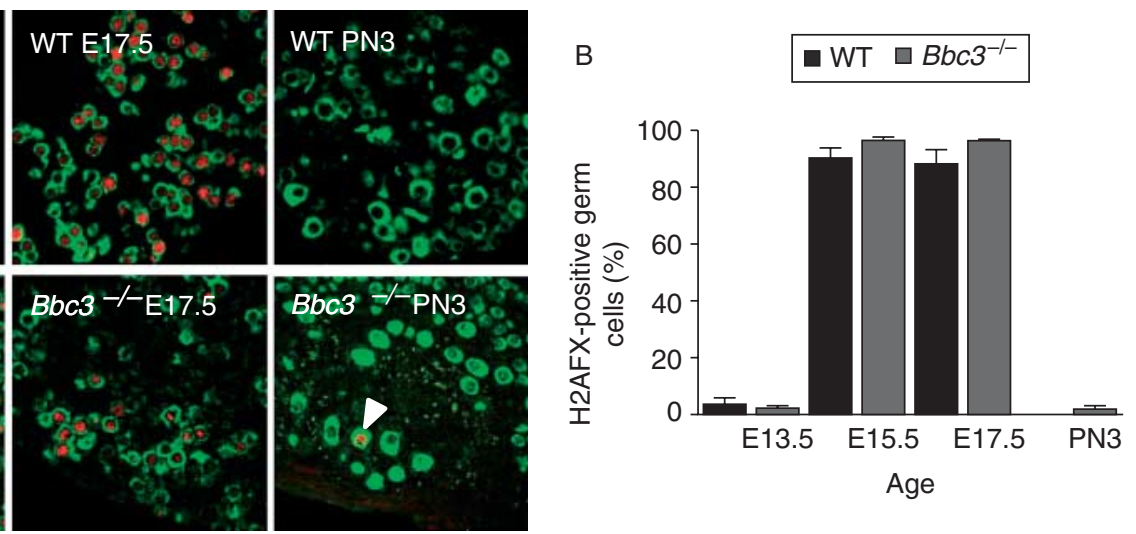

Figure $5 \mathrm{Bbc}^{-/-}$oocytes enter meiosis at the appropriate time. (A) The timing of the mitotic-meiotic transition was assessed in the ovaries of WT and $\mathrm{Bbc}^{-/-}$mice from E13.5 to PN3 by immunostaining for the meiotic marker H2AFX (red) and the germ cell marker DDX4 (green). Arrowhead indicates the persistence of $\mathrm{H} 2 \mathrm{AFX}$ in a $B b c 3^{-1-}$ oocyte at PN3. Scale bar: $50 \mu \mathrm{m}$. Data are representative of $n=3-5$ animals/age per genotype. (B) The proportions of germ cells (DDX4 positive) that were also positive for $\mathrm{H} 2 \mathrm{AFX}$ were determined in the ovaries of WT and Bbc ${ }^{-/-}$mice. Data are expressed as means \pm s.E.M.

earliest stages of ovarian development. The loss of $B b c 3$ was found to result in 2.2-fold more germ cells by E13.5, indicating that $\mathrm{BBC} 3$ acts prior to this period when proliferating germ cells are migrating or very soon after their arrival in the developing ovary. An increased number of oocytes were sustained throughout embryonic and early postnatal life to result in an overendowment of primordial follicles at PN10. These data highlight the importance of apoptosis in the regulation of the number of germ cells during migration or soon after their arrival in the gonad and indicate that BBC3mediated actions are key determinants of the size of the ovarian reserve.

To rule out the possibility that the increased numbers of germ cells in the ovaries of $B b c 3^{-/-}$mice were due to abnormally increased proliferation within the ovary, we examined germ cell mitosis at E13.5 using the mitotic marker PH3. We found no evidence for increased proliferation that might explain the increase in the number of germ cells observed in $\mathrm{Bbc}^{-/-}$mice. We also investigated the possibility that germ cells undergo prolonged proliferation in $B b c 3^{-/-}$females by staining for the meiotic marker H2AFX to determine the onset of meiosis. Our data indicate that germ cells in the ovaries of both WT and $B b c 3^{-1-}$ mice enter meiosis between E13.5 and E15.5, which is consistent with previous reports (Greenfeld et al. 2007). Interestingly, although $\mathrm{\gamma H} 2 \mathrm{AX}$ staining was no longer evident in WT oocytes at PN3, a small number of $B b c 3^{-/-}$oocytes continued to express $\mathrm{H} 2 \mathrm{AFX}$ during this stage. We also observed a slight delay in the expression of TRP63, a marker of diplotene arrest, in the ovaries of $\mathrm{Bbc}^{-/-}$mice. These data indicate that $B b c 3^{-/-}$oocytes enter meiosis at the appropriate time, but that a slight prolongation of the early meiotic prophase occurs in the absence of $B b c 3$. As all $B b c 3^{-1-}$ oocytes appeared to have progressed to meiotic arrest by PN5 and
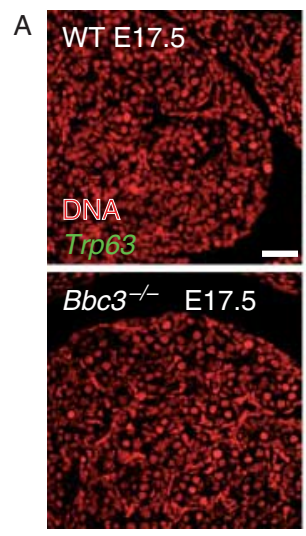
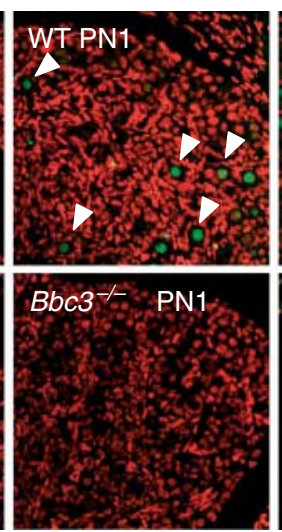
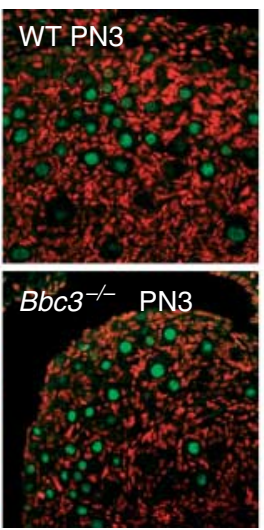

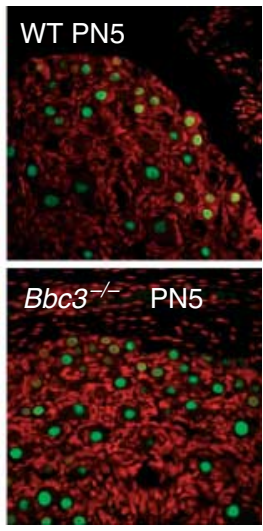

B

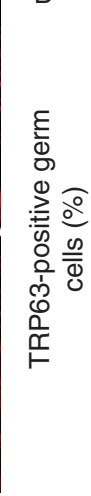

WT $\square \mathrm{Bbc3}^{-1-}$

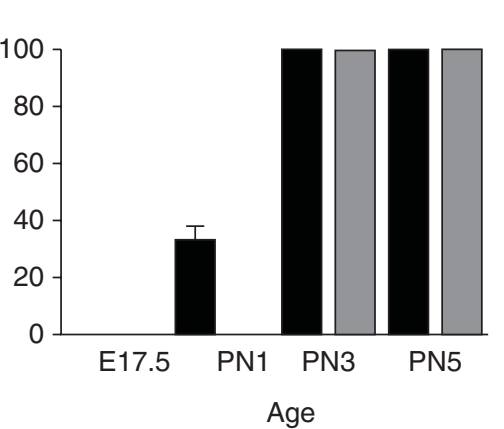

Age

Figure 6 Meiotic arrest is slightly delayed in $B b c 3^{-1-}$ oocytes. (A) The timing of the meiotic arrest was assessed in the ovaries of WT and $B b c 3^{-1-}$ mice from E17.5 to PN5 by immunostaining for the diplotene marker TRP63 (green). DNA was counterstained with TOPRO3 (red). Arrowheads indicate TAp63 staining at PN1 in WT oocytes but not in $B b c 3^{-1-}$ oocytes. Scale bar: $50 \mu \mathrm{m}$. Data are representative of $n=3-5$ animals/age per genotype. (B) The proportions of germ cells that were positive for TRP63 were determined in the ovaries of WT and $B b c 3^{-1-}$ mice. Data are expressed as means \pm S.E.M. 

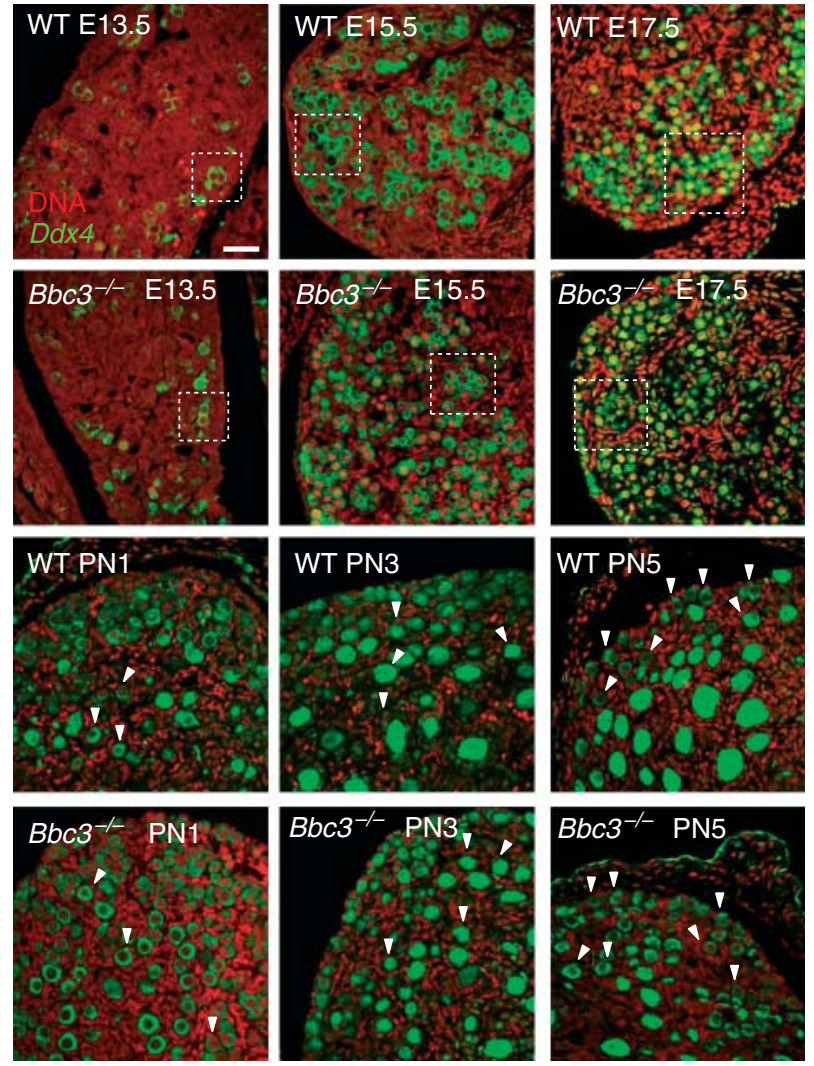

Figure 7 Germ cell nest assembly and breakdown proceed normally in $\mathrm{Bbc}^{-1-}$ ovaries. Germ cell nest formation and breakdown were assessed in the ovaries of WT and $\mathrm{Bbc}^{-/-}$mice from E13.5 to PN5 by immunostaining for the cytoplasmic germ cell marker DDX4 (green). DNA was counterstained with TOPRO3 (red). Germ cell nests are indicated by clusters of germ cells that appear to be connected with continuously stained cytoplasm. Germ cell nests are enclosed with boxes (white dashed lines). Nest breakdown and follicle formation are indicated by the appearance of individual oocytes. Individual oocytes are indicated with white arrowheads. Scale bar: $50 \mu \mathrm{m}$. Data are representative of $n=3-5$ animals/age per genotype.

$\mathrm{H} 2 \mathrm{AFX}$ could no longer be detected during this stage, the significance of this brief delay is not known.

Notably, we observed very little BBC3 expression within ovaries between E13.5 and PN5. We also did not observe a significant decrease in the number of TUNELpositive cells in the absence of $B b c 3$ between E13.5 and PN5. Furthermore, our data indicate that germ cell nest breakdown (i.e. between E17.5 and PN10 in the mouse) and follicle assembly occur normally in the absence of $B b c 3$. These data indicate that BBC3 does not play a significant role in cell apoptosis within the ovary during this period. Although it has been suggested that apoptosis may be required to facilitate nest breakdown and follicle assembly (Coucouvanis et al. 1993), work carried out by Lei \& Spradling (2013) has demonstrated that nest fragmentation actually precedes germ cell apoptosis in the ovary of mice, indicating that they are independent events. Thus, the key triggers and mediators of apoptosis responsible for massive germ cell death during this period are not known and the underlying physiological reasons for this loss are still unclear.

Although we established an essential role for BBC3 in the regulation of germ cell number, acting prior to E13.5 in mice, it is not yet clear whether BBC3 directly mediates apoptosis of germ cells or whether BBC3 acts in somatic cells, with their loss negatively affecting germ cell survival. It is also not yet understood why BBC3 is activated to eliminate germ cells during the migratory and/or mitotic phase of development. We have previously shown that BBC3 is critical for the elimination of primordial follicle oocytes that have sustained DNA damage (Kerr et al. 2012b). Thus, it is possible that germ cells with genetic damage arising from rapid and successive rounds of mitosis are also eliminated by BBC3. Consequently, future studies will exactly pinpoint when, between germ cell specification and arrival in the gonad, BBC3 mediates apoptosis and determine precisely which cells are targeted for demolition by BBC3 and will also evaluate the quality of oocytes in $\mathrm{Bbc}^{-1-}$ mice. The intrinsic apoptosis pathway has previously been shown to regulate primordial germ cell death during the migratory phase, with Bax being identified as important for the elimination of germ cells lagging in development or those that migrate to ectopic sites (Stallock et al. 2003, Runyan et al. 2006). However, a role for BBC3 in the mediation of germ cell loss during this period has never been investigated.

The findings of the present study are consistent with those of previous gene overexpression and knockout studies in mice demonstrating the importance of the BCL2-regulated apoptosis pathway in the regulation of the death of germ cells and determination of the number of follicles making up the ovarian reserve. For example, a reduction in the function of the anti-apoptotic protein $\mathrm{BCL} 2 \mathrm{~L} 1$ was found to lead to a reduced number of primordial follicles in neonatal ovaries (Rucker et al. 2000). It was demonstrated that BCL2L1 is particularly important for the survival of germ cells between E12.5 and E15.5. Similarly, deletion of the anti-apoptotic protein BCL2 was also found to reduce follicle endowment (Ratts et al. 1995), whereas the overexpression of BCL2 was found to increase initial follicle number by 1.7 -fold, though the number of primordial follicles did not remain elevated in adult life (Flaws et al. 2001, 2006). Finally, deletion of the pro-apoptotic multi$\mathrm{BH}$ domain protein $\mathrm{BAX}$ was found to result in increased germ cell survival during embryonic development, with studies indicating that BAX mediates germ cell death prior to E13.5, similar to our findings for BBC3 (Alton \& Taketo 2007, Greenfeld et al. 2007). Furthermore, deletion of Bax was found to result in a 1.4-fold increase in the number of primordial follicles at birth (Greenfeld et al. 2007), and another study indicated that the loss of Bax resulted in an elevated number of follicles throughout reproductive life, possibly due to reduced follicular atresia (Perez et al. 1999). In these mice, 
fertility was not prolonged, but age-related health problems, including bone and muscle loss, were reduced as a consequence of prolonged ovarian function (Perez et al. 1999, 2007). These studies support the notion that ovarian function, and possibly fertility, may be prolonged by even a modest increase in the number of initial primordial follicles, conferring significant benefits to health and fertility. However, it is important to note that contrary to the study carried out by Perez et al. (1999), a recent study has found no difference in the number of primordial follicles in $\mathrm{Bax}^{-/-}$mice compared with WT females at 1 year of age (Ke et al. 2013). The disparity between these two studies may be due to differences in the method of follicle counting used. For example, Perez et al. (1999) reported follicle numbers per ovary, whereas Ke et al. (2013) reported follicle numbers per standard unit of area.

In conclusion, we have shown that $\mathrm{BBC} 3$ is an important regulator of the number of embryonic germ cells, which translates into an increased number of primordial follicles established in the initial ovarian reserve. Given the established role of BBC3 in apoptosis, our data indicate that BBC3 initiates (directly or indirectly) the death of germ cells prior to meiotic entry, either during migration to the gonad or soon after their arrival. Future studies will characterise the role of $\mathrm{BBC} 3$ during this period and will also determine whether the initial over-endowment of primordial follicles conferred by the loss of $\mathrm{Bbc} 3$ persists throughout reproductive life and results in prolonged fertility.

\section{Declaration of interest}

The authors declare that there is no conflict of interest that could be perceived as prejudicing the impartiality of the research reported.

\section{Funding}

This work was supported by fellowships and grants from the National Health and Medical Research Council (NHMRC Australia; project grants \#1007027 (K J Hutt), \#1062702 (C L Scott), program grants \#494802 and \#257502, and fellowships \#441101 (J K Findlay), \#1050130 (K J Hutt), \#406675 (C L Scott), and \#461299 (A Sutherland)), the Cancer Council Victoria (Sir Edward Dunlop Fellowship in Cancer Research, C L Scott) and the Victorian Cancer Agency (Clinical Fellowship, C L Scott). This work was made possible through the Australian Cancer Research Foundation and Victorian State Government Operational Infrastructure Support and Australian Government NHMRC IRIISS.

\section{Acknowledgements}

The authors thank F McKeon for his gift of the TAp63 antibody and S Connell and I. Boundy for histology support. PHI data audit number 13-43.

\section{References}

Alton M \& Taketo T 2007 Switch from BAX-dependent to BAX-independent germ cell loss during the development of fetal mouse ovaries. Journal of Cell Science 120 417-424. (doi:10.1242/jcs.03332)

Borum K 1961 Oogenesis in the mouse. A study of the meiotic prophase. Experimental Cell Research 24 495-507. (doi:10.1016/0014-4827 (61)90449-9)

de Bruin JP \& te Velde ER Female reproductive aging: concepts and consequences. In: Togas Tulandi RGG, editor. Preservation of Fertility, London, UK: Taylor and Francis; 2004, p.1-19.

Byskov AG, Faddy MJ, Lemmen JG \& Andersen CY 2005 Eggs forever? Differentiation 73 438-446. (doi:10.1111/j.1432-0436.2005.00045.x)

Coucouvanis EC, Sherwood SW, Carswell-Crumpton C, Spack EG \& Jones PP 1993 Evidence that the mechanism of prenatal germ cell death in the mouse is apoptosis. Experimental Cell Research 209 238-247. (doi:10.1006/excr.1993.1307)

Faddy MJ \& Gosden RGA 1995 A mathematical model of follicle dynamics in the human ovary. Human Reproduction $10770-775$.

Flaws JA, Hirshfield AN, Hewitt JA, Babus JK \& Furth PA 2001 Effect of bcl-2 on the primordial follicle endowment in the mouse ovary. Biology of Reproduction 64 1153-1159. (doi:10.1095/biolreprod64.4.1153)

Flaws JA, Marion SL, Miller KP, Christian PJ, Babus JK \& Hoyer PB 2006 Effect of bcl-2 overexpression in mice on ovotoxicity caused by 4-vinylcyclohexene. Toxicology and Applied Pharmacology 215 51-56. (doi:10.1016/j.taap.2006.03.003)

Greenfeld CR, Pepling ME, Babus JK, Furth PA \& Flaws JA 2007 BAX regulates follicular endowment in mice. Reproduction 133 865-876. (doi:10.1530/REP-06-0270)

Happo L, Strasser A \& Cory S 2012 BH3-only proteins in apoptosis at a glance. Journal of Cell Science 125 1081-1087. (doi:10.1242/jcs.090514)

Hutt KJ, McLaughlin EA \& Holland MK 2006 KIT/KIT ligand in mammalian oogenesis and folliculogenesis: roles in rabbit and murine ovarian follicle activation and oocyte growth. Biology of Reproduction 75 421-433. (doi:10.1095/biolreprod.106.051516)

Ke F, Bouillet P, Kaufmann T, Strasser A, Kerr J \& Voss AK 2013 Consequences of the combined loss of BOK and BAK or BOK and BAX. Cell Death \& Disease 4 e650. (doi:10.1038/cddis.2013.176)

Kerr JB, Duckett R, Myers M, Britt KL, Mladenovska T \& Findlay JK 2006 Quantification of healthy follicles in the neonatal and adult mouse ovary: evidence for maintenance of primordial follicle supply. Reproduction 132 95-109. (doi:10.1530/rep.1.01128)

Kerr JB, Brogan L, Myers M, Hutt KJ, Mladenovska T, Ricardo S, Hamza K, Scott CL, Strasser A \& Findlay JK 2012a The primordial follicle reserve is not renewed after chemical or $\gamma$-irradiation mediated depletion. Reproduction 143 469-476. (doi:10.1530/REP-11-0430)

Kerr JB, Hutt KJ, Michalak EM, Cook M, Vandenberg CJ, Liew SH, Bouillet P, Mills A, Scott CL, Findlay JK et al. 2012b DNA damageinduced primordial follicle oocyte apoptosis and loss of fertility require TAp63-mediated induction of Puma and Noxa. Molecular Cell 48 343-352. (doi:10.1016/j.molcel.2012.08.017)

Lawson KA \& Hage WJ 1994 Clonal analysis of the origin of primordial germ cells in the mouse. Ciba Foundation Symposium 182 68-84 (discussion 84-91).

Lei L \& Spradling AC 2013 Mouse primordial germ cells produce cysts that partially fragment prior to meiosis. Development 140 2075-2081. (doi:10.1242/dev.093864)

McClellan KA, Gosden R \& Taketo T 2003 Continuous loss of oocytes throughout meiotic prophase in the normal mouse ovary. Developmental Biology 258 334-348. (doi:10.1016/S0012-1606(03)00132-5)

McLaren A 1988 The developmental history of female germ cells in mammals. Oxford Reviews of Reproductive Biology 10 162-179.

McLaren A 2000 Germ and somatic cell lineages in the developing gonad. Molecular and Cellular Endocrinology 163 3-9. (doi:10.1016/S03037207(99)00234-8)

Merino D, Giam M, Hughes PD, Siggs OM, Heger K, O'Reilly LA, Adams JM, Strasser A, Lee EF, Fairlie WD et al. 2009 The role of BH3-only protein Bim extends beyond inhibiting $\mathrm{Bcl}-2$-like prosurvival proteins. Journal of Cell Biology 186 355-362. (doi:10.1083/jcb.200905153)

Molyneaux K \& Wylie C 2004 Primordial germ cell migration. International Journal of Developmental Biology 48 537-544. (doi:10.1387/ijdb. $041833 \mathrm{~km})$ 
Motta PM, Nottola SA \& Makabe S 1997 Natural history of the female germ cell from its origin to full maturation through prenatal ovarian development. European Journal of Obstetrics, Gynecology, and Reproductive Biology 75 5-10. (doi:10.1016/S0301-2115(97)00216-9)

Myers M, Britt KL, Wreford NG, Ebling FJ \& Kerr JB 2004 Methods for quantifying follicular numbers within the mouse ovary. Reproduction 127 569-580. (doi:10.1530/rep.1.00095)

Pepling ME 2006 From primordial germ cell to primordial follicle: mammalian female germ cell development. Genesis 44 622-632. (doi:10.1002/dvg.20258)

Pepling ME \& Spradling AC 1998 Female mouse germ cells form synchronously dividing cysts. Development 125 3323-3328.

Pepling ME \& Spradling AC 2001 Mouse ovarian germ cell cysts undergo programmed breakdown to form primordial follicles. Developmental Biology 234 339-351. (doi:10.1006/dbio.2001.0269)

Perez GI, Robles R, Knudson CM, Flaws JA, Korsmeyer SJ \& Tilly JL 1999 Prolongation of ovarian lifespan into advanced chronological age by Bax-deficiency. Nature Genetics 21 200-203. (doi:10.1038/5985)

Perez GI, Jurisicova A, Wise L, Lipina T, Kanisek M, Bechard A, Takai Y, Hunt P, Roder J, Grynpas M et al. 2007 Absence of the proapoptotic Bax protein extends fertility and alleviates age-related health complications in female mice. PNAS 104 5229-5234. (doi:10.1073/pnas.0608557104)

Ratts VS, Flaws JA, Kolp R, Sorenson CM \& Tilly JL 1995 Ablation of bcl-2 gene expression decreases the numbers of oocytes and primordial follicles established in the post-natal female mouse gonad. Endocrinology 136 3665-3668. (doi:10.1210/endo.136.8.7628407)

Rucker EB III, Dierisseau P, Wagner KU, Garrett L, Wynshaw-Boris A, Flaws JA \& Hennighausen L 2000 Bcl-x and Bax regulate mouse primordial germ cell survival and apoptosis during embryogenesis. Molecular Endocrinology 14 1038-1052. (doi:10.1210/mend.14.7.0465)

Runyan C, Schaible K, Molyneaux K, Wang Z, Levin L \& Wylie C 2006 Steel factor controls midline cell death of primordial germ cells and is essential for their normal proliferation and migration. Development 133 4861-4869. (doi:10.1242/dev.02688)

Skaznik-Wikiel M, Tilly JC, Lee HJ, Niikura Y, Kaneko-Tarui T, Johnson J \& Tilly JL 2007 Serious doubts over "Eggs forever?" Differentiation $\mathbf{7 5}$ 93-99. (doi:10.1111/j.1432-0436.2006.00117.x)
Stallock J, Molyneaux K, Schaible K, Knudson CM \& Wylie C 2003 The proapoptotic gene Bax is required for the death of ectopic primordial germ cells during their migration in the mouse embryo. Development 130 6589-6597. (doi:10.1242/dev.00898)

Strasser A, O'Connor L \& Dixit VM 2000 Apoptosis signaling. Annual Review of Biochemistry 69 217-245. (doi:10.1146/annurev.biochem.69. 1.217)

Suh EK, Yang A, Kettenbach A, Bamberger C, Michaelis AH, Zhu Z, Elvin JA, Bronson RT, Crum CP \& McKeon F 2006 p63 protects the female germ line during meiotic arrest. Nature 444 624-628. (doi:10.1038/nature05337)

Tam PP \& Snow MH 1981 Proliferation and migration of primordial germ cells during compensatory growth in mouse embryos. Journal of Embryology and Experimental Morphology 64 133-147.

Telfer EE, Gosden RG, Byskov AG, Spears N, Albertini D, Andersen CY, Anderson R, Braw-Tal R, Clarke H, Gougeon A et al. 2005 On regenerating the ovary and generating controversy. Cell 122 821-822. (doi:10.1016/j.cell.2005.09.004)

Tilly JL 2001 Commuting the death sentence: how oocytes strive to survive. Nature Reviews. Molecular Cell Biology 2 838-848. (doi:10.1038/ 35099086)

Villunger A, Michalak EM, Coultas L, Mullauer F, Bock G, Ausserlechner MJ, Adams JM \& Strasser A 2003 p53- and drug-induced apoptotic responses mediated by $\mathrm{BH} 3$-only proteins puma and noxa. Science 302 1036-1038. (doi:10.1126/science.1090072)

Willis SN, Fletcher JI, Kaufmann T, van Delft MF, Chen L, Czabotar PE, lerino H, Lee EF, Fairlie WD, Bouillet $P$ et al. 2007 Apoptosis initiated when $\mathrm{BH} 3$ ligands engage multiple $\mathrm{Bcl}-2$ homologs, not Bax or Bak. Science 315 856-859. (doi:10.1126/science.1133289)

Received 21 December 2013

First decision 11 February 2014

Revised manuscript received 13 April 2014

Accepted 23 May 2014 